Rev. Latino-Am. Enfermagem

2017;25:e2754

DOI: $10.1590 / 1518-8345.0671 .2754$

www.eerp.usp.br/rlae

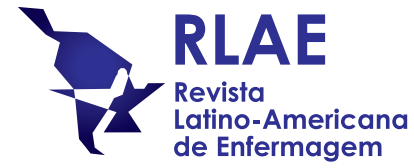

\title{
Assessment of risk of falls in elderly living at home ${ }^{1}$
}

\author{
Adriana de Azevedo Smith² \\ Antonia Oliveira Silva ${ }^{3}$ \\ Rosalina Aparecida Partezani Rodrigues ${ }^{4}$ \\ Maria Adelaide Silva Paredes Moreira ${ }^{5}$ \\ Jordana de Almeida Nogueira ${ }^{6}$ \\ Luiz Fernando Rangel Tura ${ }^{7}$
}

\begin{abstract}
Objective: to assess the risk of falls in elderly, by comparing the sociodemographic and cognitive factors, history of falls and self-reported comorbidities. Method: cross-sectional and quantitative study with 240 elderly. Data were collected based on the social profile, through the instrument of risk of falls and assessment of falls, by univariate analysis, bivariate and multiple logistic regression. The Statistical Package for the Social Sciences (SPSS) version 19 was used for statistical analysis. Results: there was a significant association of the risk of falls, as measured by the Fall Risk Score, with sex $(<0.001)$, age (0.054), cognitive status $(<0.001)$ and history of falls $(<0.001)$. All variables were statistically significant and contributed to the occurrence of falls. In logistic regression, the variables that showed association with risk of falls were: fall, with whom they live, hypertension and visual impairment. Conclusion: female gender, older elderly (over 80 years old), with low cognitive status and occurrence of previous falls in the last six months are factors that increase the prevalence of falls. In logistic regression, the variables that were associated with risk of falls were: fall, with whom they live, visual impairment and rheumatologic diseases.
\end{abstract}

Descriptors: Elderly; Accidental Falls; Risk

\footnotetext{
${ }_{1}$ Paper extrated from Master's Thesis "Social Representations and Risk Assessment os Falls in Elderly", presented to Universidade Federal da Paraíba, João Pessoa, PB, Brasil. Supported by Coordenação de Aperfeiçoamento de Pessoal de Nível Superior, PROCAD/CAPES, process \# $2324 / 2008$.

2 MSc.

${ }^{3} \mathrm{PhD}$, Associate Professor, Universidade Federal da Paraíba, João Pessoa, PB, Brazil.

${ }^{4} \mathrm{PhD}$, Full Professor, Escola de Enfermagem de Ribeirão Preto, Universidade de São Paulo, PAHO/WHO Collaborating Centre for Nursing Research Development, Ribeirão Preto, SP, Brazil.

${ }^{5} \mathrm{PhD}$, Researcher, Universidade Federal da Paraíba, João Pessoa, PB, Brazil.

${ }^{6}$ PhD, Adjunct Professor, Universidade Federal da Paraíba, João Pessoa, PB, Brazil.

${ }^{7}$ PhD, Professor, Universidade Federal do Rio de Janeiro, Rio de Janeiro, RJ, Brazil.
}

\section{How to cite this article}

Smith AA, Silva AO, Rodrigues RAP, Moreira MASP, Nogueira JA, Tura LFR. Assessment of risk of falls in elderly living at home. Rev. Latino-Am. Enfermagem. 2017;25:e2754. [Access _1 _]; Available in: DOI: http://dx.doi.org/10.1590/1518-8345.0671.2754. ${ }^{\text {month }}$ day year 


\section{Introduction}

The increasing demographic aging observed in different countries is a complex phenomenon of global relevance that reflects in various sectors of society, including healthcare.

Among the impacts and damages to the elderly's health, it was observed that the prevalence of chronic non-communicable diseases and external causes (such as falls and accidents), feature a significant magnitude and are major causes of morbidity and mortality ${ }^{(1)}$. In this context, it is important to note that the falls reach up to $32 \%$ of elderly people aged 65 to 74 years and $51 \%$ of elderly people over 85 years ${ }^{(2)}$. In a recent study, which covered a sample of 6,616 elderly residing in urban areas in 100 municipalities of 23 Brazilian states, it was observed that the prevalence of falls among them was $27.6 \%$, in the 12 months prior to the interview(3).

In the daily lives of the elderly, many factors can facilitate or promote the occurrence of falls. These factors are divided into two major groups: intrinsic, which are inherent to the person and related to the biological and psychosocial changes associated with aging; and extrinsic, which results from the interaction of the elderly with the environment, for example, quality of flooring and lighting in their residences, access to public transportation and recreational areas, among others. However, for being multifactorial events, these factors are related to the ability to maintain the skills needed to perform basic and instrumental activities of daily living, perceived as a requirement to live with independence and autonomy, so it is often difficult to report them separately(1,4-6).

Thus, the high prevalence of falls can have serious consequences on the quality of life of the elderly, which can result in prolonged hospitalization, institutionalization, restriction of activities and mobility, changes in balance and postural control, social isolation, anxiety and depression ${ }^{(7)}$. In this way, it is important to know and identify the potentiating and protective factors, in order to adopt preventive measures for these events of falls.

Therefore, changes resulting from the population aging have caused a new vision of care, which requires prioritization of the functional independence and autonomy. In this sense, the occurrence of falls interferes with biopsychosocial and economic aspects of the elderly and society, so it is important to prioritize the knowledge of risk factors and the impact of the occurrence of falls, with the aim of establishing preventive measures.

Given the above, the objective of this study was to evaluate the risk of falls among the elderly living at home, residing in the municipality of João Pessoa, Paraíba, Brazil.

\section{Methods}

Cross-sectional study with a quantitative approach, carried out in the urban area of the municipality of João Pessoa, Paraíba, Brazil, through structured interviews with the elderly living at home, in the period from November 2010 to February 2011.

Participants were elderly over 60 years, of both sexes, residents in the selected census sectors, which were pre-selected among the 617 existing sectors used by the Brazilian Institute of Geography and Statistics (IBGE). For the draw of sectors, it was taken into account the number of elderly residing in the municipality of João Pessoa-PB, totaling 61,281 , according to estimates by IBGE in 2007.

The self-weighted two-stage sample was calculated per conglomerate, through a process of probability sampling, and 20 census tracts were drawn with a probability proportional to the size of the sector, according to the 2000 census. Therefore, the Primary Sampling Unit (PSU) was the census tract, and the street was the unit drawn in the second stage. The sampling procedure occurred in two stages: setting up the same number of elderly people in the second stage, which ensures a selfweighted sampling, and therefore, each individual has a weight equal to one in the database. After the draw of the sectors, the street names were entered into the Statistical Package for the Social Sciences (SPSS) and a new draw was carried out by sector. Finally, the number of blocks was entered, and another draw was carried out. Data collection occurred in the opposite direction to the visited households, until reaching 12 elderly per sector, according to the study inclusion criteria.

It was decided, therefore, on a sample of 240 individuals, which ensured a maximum error of $6.3 \%$ with $95 \%$ probability.

Later, data collection began in the homes of the elderly and the interviews lasted approximately 60 minutes, respecting the availability of time of each elderly.

Data collection was carried out in three stages. In the first stage, it was collected information on the identification, social profile and self-reported health problems, including the following variables: age (by age group); sex (male and female); ethnicity (white, brown and black); marital status (single, married, divorced, widowed); with whom the elderly live (with or without a partner, family or non-family); education (illiterate, low educational level - one to four years-, middle - five to eight years- or high - nine or more years); monthly 
income (no income, a minimum wage, two minimum wages, three to five minimum wages or more than six minimum wage) and morbidities self-reported by the elderly people with their respective medications prescribed by the doctor. For grading the cognitive status of the elderly, the second stage of data collection, the Mini Mental State Examination (MMSE) ${ }^{(8)}$ was used for the assessment of the cognitive status.

The third stage, concerning the assessment of the risk of falls, was measured by the Fall Risk Score instrument, which predicts falls in the elderly, regardless of their causes because it shows the association of the scores with the number of falls. The scale of risk of falls, previously validated for the Brazilian population ${ }^{(9)}$, uses five criteria to assess the risk of falls, which are: 1) the presence or absence of previous falls; 2) medications used by the elderly with their respective names; 3 ) presence or absence of sensory deficit; 4) mental status, through the Mini-Mental State Examination; 5) pace, assessing the way to walk. This scale ranges from zero to eleven points and scores $\geq$ three points suggest that the elderly has a high risk of falls ${ }^{(10)}$.

Data were analyzed using SPSS (Statistical Package for the Social Science) for Windows, version 19. In univariate analysis, quantitative variables were investigated using measures of central tendency (mean and median), dispersion (Standard Deviation) and proportions for categorical variables. In bivariate analysis for qualitative variables, measures of association were carried out in contingency tables $\left(\mathrm{x}^{2}\right.$, prevalence ratio and odds ratio or prevalence of odds ratio), considering 0.05 as level of significance. For the final analysis of the main outcome - the risk of falls - multiple logistic regression was used with the following predictive variables: gender, age group, occurrence of falls, with whom they live and some of the most prevalent comorbidities, considering 0.05 as level of significance.

The Research Ethics Committee of the University Hospital Lauro Wanderley, of the Federal University of Paraíba, approved the project in accordance with the rules and guidelines for research with human beings, under opinion number 0598/10.
Participants were informed about the research development and those who agreed to participate have signed the Informed Consent Form, in two copies, one copy was given to the elderly.

\section{Results}

The results show that most interviewees are female $(69.6 \%)$. The prevalent age group was from 70 to 74 years, which corresponds to $24.2 \%$, with the range varying from 60 to 96 years, mean of 71.6 years, median of 71.0 and the Standard Deviation of \pm 7.5 .

White ethnicity predominated among the female elderly (44.3\%) and brown ethnicity predominated among elderly men (46.6\%). Regarding marital status, most were widows and married men.

It is observed that women have schooling from 5 to 8 years of study $(30.5 \%)$, followed by the illiterates (22.9\%). As for men, $28.8 \%$ reported schooling from 1 to 4 years of study and $24.7 \%$ reported middle level of education (5-8 years of study).

Most elderly people have income equivalent to one minimum wage $(45.8 \%)$, followed by 3 to 5 minimum wages $(17.5 \%)$. The minimum wage for the period in which the study was conducted was R\$510.00 in 2010 and $\mathrm{R} \$ 545.00$ in 2011.

Among the elderly, only $4.6 \%$ live alone in their homes. The others (95.4\%) live accompanied, and of these, $33.8 \%$ live with their sons and grandsons (trigenerational arrangements), $16.3 \%$ live with their spouse and sons, and $13.8 \%$ live with their spouse.

Among the variables highlighted in the study, marital status and monthly income were statistically significant.

To assess the risk of falls, such risk was associated with the following variables: gender, age group, cognitive status and occurrence of falls. The relative risk or risk ratio (RR) and prevalence odds ratio or odds ratio (OR) were statistically significant at a $p$-value $<0.05$. All variables were statistically significant, as shown in Table 1.

Table 1 - Distribution of the elderly by sex, age group, cognitive status and occurrence of falls, associated to the risk of falls. João Pessoa-PB, Brazil, $2011(n=240)$.

\begin{tabular}{|c|c|c|c|c|c|c|c|c|c|}
\hline \multirow{2}{*}{ Variable } & \multicolumn{2}{|c|}{$\begin{array}{c}\begin{array}{c}\text { High risk of } \\
\text { falls }\end{array} \\
\end{array}$} & \multicolumn{2}{|c|}{$\begin{array}{c}\text { Low risk of } \\
\text { falls }\end{array}$} & \multicolumn{2}{|c|}{ Total } & \multirow{2}{*}{$\begin{array}{c}\begin{array}{c}\text { Prevalence } \\
\text { Ratio }(95 \% \mathrm{Cl}) \\
\text { PR }\end{array}\end{array}$} & \multirow{2}{*}{$\begin{array}{c}\begin{array}{c}\text { Prevalence of Odds Ratio } \\
\text { OR }(95 \% \mathrm{Cl})\end{array} \\
\text { POR }\end{array}$} & \multirow{2}{*}{$\mathbf{p}^{*}$} \\
\hline & $\mathbf{N}$ & $\%$ & $\mathrm{~N}$ & $\%$ & $\mathbf{N}$ & $\%$ & & & \\
\hline \multicolumn{10}{|l|}{ Sex } \\
\hline Female & 96 & 57.5 & 71 & 42.5 & 167 & 100 & 1.749 & 2.761 & $<0.001$ \\
\hline Male & 24 & 32.9 & 49 & 67.1 & 73 & 100 & $1.229-2.488$ & $1.551-4.914$ & \\
\hline
\end{tabular}


Table 1 - (continuation)

\begin{tabular}{|c|c|c|c|c|c|c|c|c|c|}
\hline \multirow{2}{*}{ Variable } & \multicolumn{2}{|c|}{$\begin{array}{l}\text { High risk of } \\
\text { falls }\end{array}$} & \multicolumn{2}{|c|}{$\begin{array}{c}\text { Low risk of } \\
\text { falls }\end{array}$} & \multicolumn{2}{|c|}{ Total } & \multirow{2}{*}{$\begin{array}{c}\text { Prevalence } \\
\text { Ratio }(95 \% \mathrm{Cl}) \\
\text { PR }\end{array}$} & \multirow{2}{*}{$\begin{array}{c}\begin{array}{c}\text { Prevalence of Odds Ratio } \\
\text { OR }(95 \% \mathrm{Cl})\end{array} \\
\text { POR }\end{array}$} & \multirow{2}{*}{$\mathbf{p}^{*}$} \\
\hline & $\mathbf{N}$ & $\%$ & $\mathbf{N}$ & $\%$ & $\mathbf{N}$ & $\%$ & & & \\
\hline \multicolumn{10}{|l|}{ Age Group } \\
\hline $60-79$ years & 95 & 47.3 & 106 & 52.7 & 201 & 100 & 0.737 & 0.502 & 0.054 \\
\hline 80 years or older & 25 & 64.1 & 14 & 35.9 & 39 & 100 & $0.559-0.972$ & $0.247-1.021$ & \\
\hline \multicolumn{10}{|l|}{ Cognitive Status } \\
\hline With impairment & 39 & 79.6 & 10 & 20.4 & 49 & 100 & 1.877 & 5.296 & $<0.001$ \\
\hline Without impairment & 81 & 42.4 & 100 & 57.6 & 191 & 100 & $1.510-2.333$ & $2.498-11.231$ & \\
\hline \multicolumn{10}{|l|}{ Presented falls } \\
\hline Yes & 38 & 73.1 & 14 & 26.9 & 52 & 100 & 1.675 & 3.509 & $<0.001$ \\
\hline No & 82 & 43.6 & 106 & 56.4 & 88 & 100 & $1.329-2.112$ & $1.783-6.906$ & \\
\hline
\end{tabular}

${ }^{*} \times 2$ test; Level of significance: $p<0.05$.

In this research, it was found that the prevalence of falls in females, 1.749, was higher than in males. The prevalence of low cognitive status increases the risk of falls, 1.877 , compared to the elderly people who did not suffered falls. The prevalence of falls among elderly people who have suffered previous falls in the last 6 months, 1.675, was higher compared to those who have not suffered falls.

Table 2 shows the association of the prevalent comorbidities with the risk of falls. Among them, stand out the systemic arterial hypertension (SAH), visual impairment, spinal problems, osteoporosis and rheumatic diseases as predictive factors for the occurrence of falls. Among the assessed comorbidities, obesity was the only one that was not statistically significant.

It was also noted that elderly people affected by SAH $(p<0.001)$ present a risk of falls approximately seven times higher than those who are not affected by this morbidity. Having visual deficit $(p<0.001)$ and depression ( $p<0.001)$ increases in 1.929 and 1.867 times, respectively, the chances of falls.

Other comorbidities were asked during this study; however, it is not emphasized those little reported.

Table 2 - Distribution of elderly according to the self-reported comorbidities most prevalent, in relation to the risk of falls. João Pessoa-PB, Brazil, 2011 ( $n=240)$.

\begin{tabular}{|c|c|c|c|c|c|c|c|}
\hline \multirow{2}{*}{ Comorbidities } & \multicolumn{2}{|c|}{$\begin{array}{c}\text { High } \\
\text { Risk for Falls }\end{array}$} & \multicolumn{2}{|c|}{$\begin{array}{c}\text { Low } \\
\text { Risk for Falls }\end{array}$} & \multirow{2}{*}{$\begin{array}{c}\text { Prevalence Ratio } \\
\text { PR }(95 \% \mathrm{Cl}) \\
\text { PR }\end{array}$} & \multirow{2}{*}{$\begin{array}{c}\begin{array}{c}\text { Prevalence of Odds Ratio } \\
\text { OR }(95 \% \mathrm{Cl})\end{array} \\
\text { POR }\end{array}$} & \multirow{2}{*}{$\mathbf{p}^{*}$} \\
\hline & $\mathbf{N}$ & $\%$ & $\mathbf{N}$ & $\%$ & & & \\
\hline \multicolumn{8}{|l|}{ Anxiety/Panic Disorder } \\
\hline Yes & 32 & 68.1 & 15 & 31.9 & 1.493 & 2.545 & \\
\hline No & 88 & 45.6 & 105 & 54.4 & $1.164-1.916$ & $1.295-5.002$ & 0.006 \\
\hline \multicolumn{8}{|l|}{ Osteoarthritis/arthrosis } \\
\hline Yes & 52 & 64.2 & 29 & 35.8 & 1.501 & 2.400 & \\
\hline No & 68 & 42.8 & 91 & 57.2 & $1.178-1.913$ & $1.381-4.169$ & 0.002 \\
\hline \multicolumn{8}{|l|}{ Hearing impairment } \\
\hline Yes & 29 & 74.4 & 10 & 25.6 & 1.642 & 3.505 & \\
\hline No & 91 & 45.3 & 110 & 54.7 & $1.293-2.086$ & $1.622-7.575$ & 0.001 \\
\hline \multicolumn{8}{|l|}{ Diabetes Mellitus } \\
\hline Yes & 35 & 62.5 & 21 & 37.5 & 1.353 & 1.941 & 0.033 \\
\hline No & 85 & 46.2 & 99 & 53.8 & $1.047-1.747$ & $1.051-3.586$ & \\
\hline
\end{tabular}


Table 2 - (continuation)

\begin{tabular}{|c|c|c|c|c|c|c|c|}
\hline \multirow{2}{*}{ Comorbidities } & \multicolumn{2}{|c|}{$\begin{array}{c}\text { High } \\
\text { Risk for Falls }\end{array}$} & \multicolumn{2}{|c|}{$\begin{array}{c}\text { Low } \\
\text { Risk for Falls }\end{array}$} & \multirow{2}{*}{$\begin{array}{c}\text { Prevalence Ratio } \\
\text { PR }(95 \% \mathrm{Cl}) \\
\text { PR }\end{array}$} & \multirow{2}{*}{$\begin{array}{c}\begin{array}{c}\text { Prevalence of Odds Ratio } \\
\text { OR }(95 \% \mathrm{Cl})\end{array} \\
\text { POR }\end{array}$} & \multirow{2}{*}{$\mathbf{p}^{*}$} \\
\hline & $\mathbf{N}$ & $\%$ & $\mathbf{N}$ & $\%$ & & & \\
\hline \multicolumn{8}{|l|}{ Depression } \\
\hline Yes & 29 & 82.9 & 6 & 17.1 & 1.867 & 6.055 & $<0.001$ \\
\hline No & 91 & 44.4 & 114 & 55.6 & $1.506-2.314$ & $2.410-12.212$ & \\
\hline \multicolumn{8}{|l|}{ Arterial hypertension } \\
\hline Yes & 98 & 67.6 & 47 & 32.4 & 6.919 & 2.918 & $<0.001$ \\
\hline No & 22 & 23.3 & 73 & 76.8 & $3.835-12.482$ & $1.989-4.282$ & \\
\hline \multicolumn{8}{|l|}{ Obesity } \\
\hline Yes & 9 & 64.3 & 5 & 35.7 & 1.309 & 1.865 & 0.271 \\
\hline No & 111 & 49.1 & 115 & 50.9 & $0.867-1.977$ & $0.606-5.738$ & \\
\hline \multicolumn{8}{|l|}{ Osteoporosis } \\
\hline Yes & 37 & 62.7 & 22 & 37.3 & 1.368 & 1.986 & 0.025 \\
\hline No & 83 & 45.9 & 98 & 54.1 & $1.062-1.760$ & $1,086-3.630$ & \\
\hline \multicolumn{8}{|l|}{ Spine Problems } \\
\hline Yes & 60 & 60.0 & 40 & 40.0 & 1.400 & 2.000 & 0.009 \\
\hline No & 60 & 42.9 & 80 & 57.1 & $1.091-1.797$ & $1.187-3.370$ & \\
\hline \multicolumn{8}{|l|}{ Visual impairment } \\
\hline Yes & 72 & 68.8 & 33 & 31.4 & 1.929 & 3.955 & $<0.001$ \\
\hline No & 48 & 35.5 & 87 & 67.5 & $1.485-2.505$ & $2.300-6.801$ & \\
\hline
\end{tabular}

*x2 test; Level of significance: $p<0,05$.

Table 3 shows the logistic regression results, which were achieved through saturated regression model, several predictors were analyzed such as sex, age group, occurrence of falls, with whom they live and the four most prevalent comorbidities: SAH, visual impairment, spine problems and rheumatic diseases. The variables associated with the risk of falls were occurrence of falls, with whom they live, visual impairment and rheumatologic diseases. As for the occurrence of falls, prevalence of high risk, 2.831, was higher than low risk.

Table 3 - Logistic regression analysis including the risk of falls and predictors. João Pessoa- PB, Brazil, $2011(n=240)$.

\begin{tabular}{|c|c|c|c|c|c|c|}
\hline \multirow{2}{*}{ Variable } & \multicolumn{2}{|c|}{ High risk of falls } & \multicolumn{2}{|c|}{ Low risk of falls } & \multirow{2}{*}{$\begin{array}{c}\text { Prevalence of Odds Ratio } \\
\text { POR }\end{array}$} & \multirow{2}{*}{$\mathbf{p}^{*}$} \\
\hline & $\mathbf{N}$ & $(\%)$ & $\mathbf{N}$ & $(\%)$ & & \\
\hline \multicolumn{7}{|l|}{ Sex } \\
\hline Female & 96 & 57.5 & 71 & 42.5 & 1.248 & 0.609 \\
\hline Male & 24 & 32.9 & 49 & 67.1 & $0.534-2.916$ & \\
\hline \multicolumn{7}{|l|}{ Age group } \\
\hline $60-79$ years & 95 & 47.3 & 106 & 52.7 & 0.502 & 0.061 \\
\hline 80 years or older & 25 & 64.1 & 14 & 35.9 & $0.244-1.033$ & \\
\hline \multicolumn{7}{|l|}{ Presented falls } \\
\hline Yes & 38 & 73.1 & 14 & 26.9 & 2.831 & 0.014 \\
\hline No & 82 & 43.6 & 106 & 56.4 & $1.234-6.496$ & \\
\hline
\end{tabular}


Table 3 - (continuation)

\begin{tabular}{|c|c|c|c|c|c|c|}
\hline \multirow{2}{*}{ Variable } & \multicolumn{2}{|c|}{ High risk of falls } & \multicolumn{2}{|c|}{ Low risk of falls } & \multirow{2}{*}{$\frac{\text { Prevalence of Odds Ratio }}{\text { POR }}$} & \multirow{2}{*}{$\mathbf{p}^{*}$} \\
\hline & $\mathbf{N}$ & $(\%)$ & $\mathbf{N}$ & $(\%)$ & & \\
\hline Alone & 2 & 18.2 & 9 & 81.8 & 7.273 & 0.038 \\
\hline Accompanied & 71 & 31.0 & 158 & 69.0 & $1.113-47.547$ & \\
\hline \multicolumn{7}{|l|}{ Morbidity } \\
\hline \multicolumn{7}{|l|}{ Arterial hypertension } \\
\hline Yes & 98 & 67.6 & 47 & 32.4 & 1.748 & 0.135 \\
\hline No & 22 & 23.3 & 73 & 76.8 & $0.841-3.631$ & \\
\hline \multicolumn{7}{|l|}{ Visual impairment } \\
\hline Yes & 72 & 68.6 & 33 & 31.4 & 8.189 & $<0.001$ \\
\hline No & 48 & 35.6 & 87 & 67.5 & $4.079-16.442$ & \\
\hline \multicolumn{7}{|l|}{ Spine Problems } \\
\hline Yes & 60 & 60.0 & 40 & 40.0 & 1.180 & 0.629 \\
\hline No & 60 & 42.9 & 80 & 57.1 & $0.603-2.308$ & \\
\hline \multicolumn{7}{|l|}{ Rheumatic diseases } \\
\hline Yes & 52 & 64.2 & 29 & 35.8 & 4.200 & $<0.001$ \\
\hline No & 68 & 42.8 & 91 & 57.2 & $2.166-8.144$ & \\
\hline
\end{tabular}

*Multiple logistic regression; Level of significance: $p<0.05$.

The remaining predictors were statistically significant when evaluated separately, however, they were not statistically significant in logistic regression.

\section{Discussion}

Falls are frequent events, however, for being multifactorial, it is difficult to establish a single risk factor for their occurrence. Thus, the risk of falls was associated with demographic and cognitive factors, occurrence of falls and self-reported comorbidities.

In a study on the assessment of the prevalence and factors associated with falls in 2,096 individuals aged over 65 years in various states of Nigeria, it was observed sociodemographic characteristics, visual impairment, chronic physical conditions and insomnia. It was found that the major risk factors for falls were female gender, aged above 80 years, 7-12 years of study and low or medium socioeconomic status ${ }^{(11)}$.

Other studies have found greater propensity of falls among females compared to males and this difference is explained in terms of the physiological characteristics and bone and muscle structure, hormonal changes associated with menopause, as well as performing multiple tasks ${ }^{(9,12-13)}$.
In this context, an observational and multicentric study conducted in the United States and Europe with 7,897 women diagnosed with post-menopausal osteoporosis, undergoing treatment at the time or prior to the survey, assessed which factors interfered in the quality of life of these women and found great impact of fear to fall on the quality of life(14).

In this study, it was observed that advanced age, higher consumption of medications and poor perception of the health status of the elderly, were factors that predisposed the falls, considering that be a male and literate are protective factors for these events. These results were consistent with a study conducted in the coverage area of basic health units, in 41 municipalities in seven Brazilian states, with a sample of 4,003 subjects over 65 years old. Such study showed a higher prevalence of falls associated with advanced age, sedentary lifestyle, self-perception of health status as poor and higher number of medications of continuous use $^{(1)}$.

On the other hand, literature shows that the risk of falls increases in subjects with cognitive impairment and score from 24 to 30 points in the Mini-Mental State Examination. These data are similar to those found in the present study, which occur due to visualspatial disorientation, leading to a poor perception of 
environmental risks and an erroneous assessment of their own skills(13). Therefore, a study carried out in the United States ${ }^{(15)}$ with 175 elderly over 65 years old, with high risk of falls and living in a community, assessed whether cognitive deficits increased the risk of falls. The authors concluded that there is an association between cognitive decline and increased risk of these events. In this context, it is worth noting that the cognitive assessment through the MMSE was based on the same score used by Bertolucci et al ${ }^{(8)}$, whose study carried out in 1994, has established the following cutoffs: 13 points for illiterate elderly people, 18 points for the elderly with 1 to 7 years of study and 26 points for the elderly with 8 or more years of study.

Among the risk factors related to the individual (Intrinsic) and associated to the events of falls discussed in the literature, is the decrease of sensory function, which is necessary for postural control, and whose components are: decreased visual capability and hearing impairment. Both are statistically related to the risk of falls, and in association with vestibular and proprioceptive disorders result in the reduction of the information on the axial balance and consequently, in increased reaction time to dangerous situations ${ }^{(16)}$.

Other factors that may contribute to the falls are the changes in the Central Nervous System (CNS) and the musculoskeletal system disorders that accompany the aging process. These physiological events lead to a reduction in the density of the long bones and spine, with alterations in bone mineral balance and even more severe reductions, which may result in osteopenic and osteoporotic tissues ${ }^{(12)}$ also observed in the present study.

Studies reported in the literature and conducted with individuals in the community, have suggested that elderly patients who experienced previous falls are at increased risk of recurrence of these episodes, especially the elderly aged over 80 years, living alone, with complaints of dizziness, depressive symptoms and arthritis(17-18).

Multiple comorbidities may also favor the occurrence of falls as reported in the literature, since the prevalence of chronic diseases increases the possibilities of this event and drug interactions due to the use of multiple drugs ${ }^{(18-19)}$. Drug interactions (3 or more per day) or increased doses of psychoactive medications are associated with an increased number of hospitalizations due to falls.
Other factors that may contribute to the risk of falls are depression and change in cognitive status because they reduce the willingness to carry out tasks, which causes muscle weakness and culminates with difficulty of walking(20-21). Another author points out that patients with depression need to use medications such as the benzodiazepines, which may also contribute to the occurrence of falls in elderly ${ }^{(9)}$.

In a study on the factors associated with chronic diseases, with 385 elderly patients attended in the Family Health Strategy in Teófilo Otoni/Minas Gerais, found a significant prevalence of SAH (69.9\%). In addition, $20 \%$ of the elderly have reported musculoskeletal problems ${ }^{(22)}$. Another study evaluating visual impairment, chronic physical conditions and insomnia in 2,096 individuals aged over 65 years in various states of Nigeria, found that the prevalence of falls increased in the following conditions: arthritis, pain in the thoracic and cervical spine and other pains, visual impairment and insomnia(11). These results are relevant and corroborate the present study.

Articular diseases are common in the elderly and may contribute to immobility, resulting in pain and postural imbalance, favoring the occurrence of falls ${ }^{(19)}$.

In this study, logistic regression through saturated regression model showed that the variables associated with the risk of falls were: fall, with whom they live, $\mathrm{SAH}$ and visual impairment. These findings were corroborated by a study conducted in China, which found a prevalence of $18 \%$ of falls and these were associated with the age range between 60 and 70 years old, female gender, decreased physical activity, visual impairment, living alone and with health problems, such as diabetes mellitus(23).

Although this study has emphasized the sociodemographic characteristics and intrinsic factors of falls (inherent to the individual), the factors related to the environment should also be prioritized, since the occurrence of these events due to environmental inadequacies, can be minimized with the adoption of a small number of measures ${ }^{(24)}$.

\section{Conclusion}

The results of this study lead to the following conclusions: (1) The association of the risk of falls, measured by Fall Risk Score, with sex, age, cognitive status and occurrence of falls, shows that all the variables presented statistical significance; (2) Be female, older elderly (above 80 years), with low 
cognitive status and have experienced previous falls in the last six months, increase the prevalence of falls;

(3) The self-reported morbidities that were statistically related with the occurrence of falls were: hypertension, visual impairment, spinal problems, osteoporosis and rheumatic diseases; (4) in logistic regression through saturated regression model, the variables associated with the risk of falls were: fall, with whom they live, visual impairment and rheumatologic diseases.

Falls are associated with a number of factors, so the multidisciplinary knowledge is essential to provide information on the prevention and identification of elderly at risk, justifying the need for this study. In this context, further studies of this nature on a larger scale are needed, since the cross-sectional design of this study positively influences the behavior of health professionals, however, this type of study design does not allow its temporal sequence, and the exposure to the factors evaluated cannot be monitored directly, which characterizes the possible limitations of this study.

\section{References}

1. Freitas MG, Bonolo PF, Moraes EN, Machado CJ. Idosos atendidos em serviços de urgência no Brasil: um estudo para vítimas de quedas e de acidentes de trânsito. Ciênc Saúde Coletiva. 2015;20(3):701-12.

2. Zijlstra GAR, Van Haastreg JCM, Van Eijk JTM, Van Rossum E, Stalenhoef PA, Kempen GIJ. Prevalence and correlates of fear of falling, and associated avoidance of activity in the general population of community-living older people. Age Ageing. 2007;36(3):304-9.

3. Siqueira FV, Facchini LA, Silveira DS, Piccini RX, Tomasi $E$, Thumé $E$ et al. Prevalence of falls in elderly in Brazil: a countrywide analysis. Cad Saúde Pública. 2011;27(9):1819-26.

4. Gawryszewski VP. Importância das quedas no mesmo nível entre idosos no estado de São Paulo. Rev Assoc Med Bras. 2010;56(2):162-7.

5. Nunes MCR, Ribeiro RCL, Lina EFPL, Sylvia CF. Influência das características sóciodemográficas e epidemiológicas na capacidade funcional de idosos residentes em Ubá, Minas Gerais. Rev Bras Fisioter. 2009;13(5):376-82.

6. Ferreira OGL, Maciel SC, Silva AO, Santos WS, Moreira MASP. O envelhecimento ativo sob o olhar de idosos funcionalmente independentes. Rev Esc Enferm USP. 2010;44(4):1065-9.
7. Lopes KT, Costa DF, Santos LF, Castro DP, Bastone AC. Prevalência do medo de cair em uma população de idosos da comunidade e sua correlação com mobilidade, equilíbrio dinâmico, risco e histórico de quedas. Rev Bras Fisioter. 2009;13(3):223-9.

8. Bertolucci PHF, Brucki SM, Campacci SR, Juliano Y. Mini- Exame do Estado Mental em uma População Geral: Impacto da Escolaridade. Arq Neuropsiquiatr. 1994;52(1):1-7.

9. Schiaveto FV. Avaliação do risco de quedas em idosos na comunidade [Dissertação]. Ribeirão Preto (SP): Escola de Enfermagem de Ribeirão Preto da Universidade de São Paulo; 2008.

10. Padubidri A, Al Snih S, Samper-Ternent R, Markides $\mathrm{KS}$, Ottenbacher KJ, Raji MA. Falls and cognitive decline in Mexican Americans 75 years and older. Clin Interv Aging. 2014; 9:719-26.

11. Bekibele CO, Gureje O. Fall Incidence in a Population of Elderly Persons in Nigeria. Gerontology. 2010;56:278-83.

12. Steinman BA, Pynoos J, Nguyen AQD. Fall Risk in Older Adults. Roles of Self-Rated Vision, Home Modifications, and Limb Function. J Aging Health. 2009;21(5):655-76. 13. Boyd R, Stevens JA. Falls and fear of falling: burden, beliefs and behaviours. Age Ageing. 2009;38(4):423-8. 14. Guillemin F, Martinez L, Calvert M, Cooper C, Ganiats T, Gitlin M, et al. Fear of falling, fracture history, and comorbidities are associated with health-related quality of life among European and US women with osteoporosis in a large international study. Osteoporos Int. $2013 ; 24(12): 3001-10$.

15. Gleason CE, Gangnon RE, Fischer BL, Mahoney JE. Increased risk for falling associated with subtle cognitive impairment: secondary analysis of a randomized clinical trial. Dement Geriatr Cogn Disord. 2009;27(6):557-63. 16. Soares WJS, Moraes SA, Ferriolli E, Perracini MR. Fatores associados a quedas e quedas recorrentes em idosos: estudo de base populacional. Rev Bras Geriatr Gerontol. 2014; 17(1):49-60.

17. Moreno NS, André APR. Características audiológicas de idosos com Vertigem Posicional Paroxística Benigna. Rev Bras Otorrinolaringol. 2009;75(2):300-4.

18. Pratt NL, Ramsay EN, Kalisch ELM, Nguyen TA, Barratt JD, Roughead EE. Association Between Use of Multiple Psychoactive Medicines and Hospitalization for Falls: Retrospective Analysis of a Large Healthcare Claim Database. Drug Safety. 2014;37(7):529-35. 
19. Steinman BA, Pynoos J, Nguyen AQD. Fall Risk in Older Adults. Roles of Self-Rated Vision, Home Modifications, and Limb Function. J Aging Health. 2009;21(5):655-76. 20. Hamra A, Ribeiro MB, Miguel OF. Correlação entre fratura por queda em idosos e uso prévio de medicamentos. Acta Ortop Bras. 2012;15(3):143-5.

21. Fhon JRS, Rodriguez MMP, Morote GAG, Rimachi RIC, Wehbe SCCF, Rodrigues RAP. Risk of falls i the elderly to come to day two centers. Horiz Med. 2014;14(3):12-8. 22. Fiedler MM, Peres KG. Capacidade funcional e fatores associados em idosos do Sul do Brasil: um estudo de base populacional. Cad Saúde Pública. 2008;24(2):40915.

23. Yu PL, Qin ZH, Shi J, Zhang J, Xin MZ, Wu ZL, et al. Prevalence and related factors of falls among the elderly in an urban community of Beijing. Biomed Environ Sci. 2009;22:179-87.

24. Pinho TAM, Silva AO, Tura LFR, Moreira MASP, Gurgel $S N$, Smith AAF, et al. Avaliação do risco de quedas em idosos atendidos em Unidade Básica de Saúde. Rev Esc Enferm USP. 2012;46(2):320-7. Creative Commons (CC BY).

This license lets others distribute, remix, tweak, and build upon your work, even commercially, as long as they credit you for the original creation. This is the most accommodating of licenses offered. Recommended for maximum dissemination and use of licensed materials. 